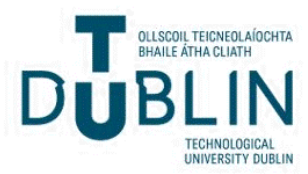

Technological University Dublin

ARROW@TU Dublin

Articles

School of Food Science and Environmental

Health

2019

\section{Laser-induced breakdown spectroscopy for food authentication}

\author{
Maria Markiewicz-Keszycka \\ Technological University Dublin, Maria.MarkiewiczKeszycka@TUDublin.ie \\ Raquel Cama-Moncunill \\ University College Dublin \\ Maria Piedad Casado-Gavalda \\ Technological University Dublin, maria.casado@tudublin.ie
}

See next page for additional authors

Follow this and additional works at: https://arrow.tudublin.ie/schfsehart

Part of the Food Science Commons, and the Medicine and Health Sciences Commons

\section{Recommended Citation}

Maria Markiewicz-Keszycka, Raquel Cama-Moncunill, Maria Pietat Casado-Gavalda, Carl Sullivan, Patrick $\mathrm{J}$ Cullen, Laser-induced breakdown spectroscopy for food authentication, Current Opinion in Food

Science, Volume 28, 2019, Pages 96-103, ISSN 2214-7993, DOI: 10.1016/j.cofs.2019.10.002.

(https://www.sciencedirect.com/science/article/pii/S2214799319300694)

This Article is brought to you for free and open access by the School of Food Science and Environmental Health at ARROW@TU Dublin. It has been accepted for inclusion in Articles by an authorized administrator of ARROW@TU Dublin. For more information, please contact arrow.admin@tudublin.ie, aisling.coyne@tudublin.ie, gerard.connolly@tudublin.ie.

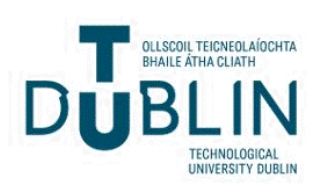


Authors

Maria Markiewicz-Keszycka, Raquel Cama-Moncunill, Maria Piedad Casado-Gavalda, Carl Sullivan, and P. J. Cullen 


\section{Laser-induced breakdown spectroscopy for food authentication \\ Maria Markiewicz-Keszycka ${ }^{1}$, Raquel Cama-Moncunill ${ }^{2}$, Maria Pietat Casado-Gavalda ${ }^{1}$, Carl Sullivan ${ }^{1}$ and Patrick J Cullen ${ }^{1,3}$}

\begin{abstract}
With the globalisation of food markets, food authentication has become a significant concern worldwide to ensure food safety and to avoid origin and quality fraud. A multi-elemental fingerprint is a powerful tool for detection of adulterants and geographical origin of foods. Laser-induced breakdown spectroscopy (LIBS) is a promising technique that can provide a mineral fingerprint of food products. LIBS allows a rapid, high-throughput, micro-destructive and multi-elemental analysis of a wide range of samples type. It has already been demonstrated by several authors that LIBS can be successfully used for food authentication. Although LIBS shows excellent potential for at-line or portable applications, improvement in sensitivity of trace elements detection, sample preparation, data analysis and instrument miniaturisation are needed.
\end{abstract}

\footnotetext{
Addresses

${ }^{1}$ School of Food Science and Environmental Health, Dublin Institute of Technology, Cathal Brugha St., Dublin 1, Ireland

${ }^{2}$ School of Agriculture and Food Science, University College Dublin, Belfield, Dublin 4, Ireland

${ }^{3}$ Centre for Advanced Food Enginomics, School of Chemical and

Biomolecular Engineering, University of Sydney, Sydney, Australia

Corresponding author:

Markiewicz-Keszycka, Maria (maria.kesz@gmail.com)
}

\author{
Current Opinion in Food Science 2019, 28:96-103 \\ This review comes from a themed issue on Foodomics \\ Edited by David I Ellis \\ For a complete overview see the Issue and the Editorial \\ Available online 14th October 2019 \\ https://doi.org/10.1016/j.cofs.2019.10.002 \\ 2214-7993/৫ 2019 Elsevier Ltd. All rights reserved.
}

\section{Introduction}

Food safety and authenticity are a major concern worldwide. Food adulterations occur globally, and factors such as increased demand for value-added products may provide an opportunity for illegal economic profits [1]. Fraudulent and deceptive practices in the agri-food sector commonly involve the replacement of ingredients with cheaper and lower quality alternatives, use or addition of illegal substances, mislabelling of the products from animal species, incorrect compositional descriptions or false claims including organic, free-range, wild-caught, and so on [2-4]. Food adulteration is a serious issue as it may cause public health problems. Addition of prohibited substances to the food, substitution of species by a lower quality counterpart, use of prohibited drugs and growth promoters in animal production have resulted in numerous food scares [5,6]. The recent examples of food scandals include 2013 horsemeat scandal in Ireland and UK, 2011 phthalate-tainted food in Taiwan, 2008 baby milk melamine incidence in China and 2008 crisis involving dioxin contamination of food and foodstuff in Ireland [7-11]. Other current issues include contamination of food with allergens and the presence of pesticides residues in fruits, vegetables, spices and herbs $[12,13]$. Accordingly, food authorities worldwide have developed and enforced many regulations on food safety and authenticity. Furthermore, the detection and prevention of food fraud are a prime concern for the food industry as fraudulent practices affect the quality of their products and consumer confidence [14].

In Europe, these regulations not only focus on protecting human health but also consumers' interests [15]. Consumers are entitled to know what they are purchasing and eating, as well as the provenance of their food $[15,16]$. Consequently, accurate and reliable labelling is crucial to inform consumers correctly. Foodstuffs under European law must be labelled with a description of the product, a list of ingredients and the country of origin or place of provenance, as well as other information [16]. While not necessarily unsafe, mislabelling, either intentional or unintentional, may deceive consumers as to the nature of the product and consequently affect their eating habits [2].

For all these reasons, food authentication has become a top priority and so has the development of fast and costeffective analytical techniques capable of verifying the integrity, safety and origin of foods.

\section{Reference methods for food authentication}

Current trends in analytical food authentication include fingerprinting techniques, which refer to those methods that display multiple non-targeted parameters providing a characteristic signal/profile of the sample [1,17]. Methods based on mass spectrometry and chromatography typically provide fingerprints of extracted or digested samples $[14,17]$. 
Vibrational spectroscopic techniques combined with chemometrics also provide a characteristic spectrum - a fingerprint of each food that allows its identification and differentiation. These techniques allow very a highspeed, high-throughput and non-destructive analysis of a wide range of sample types without laborious sample preparation [18]. Near-infrared spectroscopy (NIR), Fourier transform infrared (FT-IR) and Raman spectroscopy are found to be useful for detection of food adulteration and have been proved to be useful in distinguishing the provenance of certain agricultural products [19-22].

Techniques based on stable isotopes (2H, 13C, 15N, 18O, $34 \mathrm{~S}$ and $87 \mathrm{Sr}$ ) such as nuclear magnetic resonance (NMR) and isotope ratios mass spectroscopy (IRMS) are considered as powerful tools for assessing food origin. These analyses allow not only identification of the geographical origin of food but also the feeding regime of animals the food was produced from $\left[23^{\circ}, 24\right]$. The basis for discrimination lies in the fact that the ratios of elements such as $2 \mathrm{H} / 1 \mathrm{H}, 13 \mathrm{C} / 12 \mathrm{C}$ can vary depending on the geographical origin of soil, water and feed used on a farm [25]. However, in certain situations, the results are difficult to interpret as climate, continent and topography can all influence isotopic fractionation. Taking into consideration all these sources of variations and relativity of the measurements, a well-conceived database is essential for these methods to be useful and accurate [24].

Another powerful tool for food authentication is based on the multi-elemental fingerprinting of food products. The pattern of macro and micronutrients, trace elements and lanthanides or rare earth elements (REE) in rocks and soils gives insight into their history. Plants growing on these soils take specific elements, and their level in animal products is associated with their concentration in soil and feed [26]. Similarly, as isotopes certain elements are very stable throughout this cycle; thus, they seem to be good candidates to provide a reliable fingerprint. Mineral fingerprints have been proven to provide valuable information for traceability and authenticity of wines, honey, herbs and other types of food and brewages $\left[27,28,29^{\circ}, 30\right]$.

Atomic emission spectroscopic techniques such as inductively coupled plasma-mass spectrometry (ICP-MS), inductively coupled plasma-optical emission spectrometry (ICP-OES) and laser-induced breakdown spectroscopy (LIBS) allow elemental fingerprinting of foods which can be used for both origin and adulteration testing $\left[3,29^{\circ}, 31\right]$. Although ICP-MS is frequently the most accurate technique for elemental analysis because of the simple, easily interpreted spectra and the exceptionally low limits of detection, it not only produces large amounts of toxic waste, but also requires expensive reagents, gases and laborious sample preparation. As such, it is not suited for rapid screening analysis at the production or importation site [31].
Laser-induced breakdown spectroscopy (LIBS) is a promising fingerprinting technique which uses highly energetic laser pulses as an excitation source and offers rapid analysis, no need for chemical reagents and minimal sample preparation as advantages [32]. These characteristics make LIBS an optimal technology for routine control analysis of foods. This review presents the principals of the technique, the latest applications of LIBS on food authentication together with our opinion on the potential and future trends of the method.

\section{Principles of LIBS}

LIBS is a relatively new technique that allows a rapid, highthroughput, micro-destructive analysis of a wide range of sample types. The technique is based on optical emission spectroscopy (Figure 1). The laser which is focused on the sample creates a plasma composed of atoms, ions and electrons which emits light as the plasma cools down (Figure 2). The emitted radiation is detected using a spectrometer, and the intensity of light as a function of wavelength creates a spectrum that can provide identification as well as concentration information about the various elements present in the sample [31]. The spectrum covering the range from 190 to $850 \mathrm{~nm}$ is typically analysed with LIBS. The spectra contain a large amount of data, including background and spectral peaks that are element-related. The use of chemometrics allows the extraction of useful information and the creation of an elemental fingerprint that can be used to confirm the identity of a sample. A typical LIBS set-up is presented in Figure 3.

The combination of LIBS with chemometrics has shown successful results for samples classification and authentication $\left[33,34,35^{\circ}, 36\right]$. The initial step in the analysis of LIBS data is spectral pre-processing, which includes baseline correction, normalisation, overlapping-peaks identification, outlier removal and noise reduction [37]. Supervised and unsupervised techniques can further classify pre-processed LIBS data. Examples of unsupervised techniques include principal component analysis (PCA) and hierarchical cluster analysis (HCA) [30,38]. These techniques are usually employed to reduce data size and select most relevant LIBS bands as well as to investigate groups/patterns within the data set [39-41]. Supervised techniques are more powerful as they allow the prediction of an output variable based on a model previously developed with a training data set [14]. Supervised techniques for classification include partial least squares-discriminant analysis (PLS-DA), random forest (RF), artificial neural network (ANN), support vector machine (SVM), k-nearest neighbours (k-NN) and linear discriminant analysis (LDA) [36,42,43]; while for quantification, partial least squares regression (PLSR) is the most commonly employed [30]. Unsupervised and supervised methods are complementary and can be superimposed. These methods have been proved to be effective 


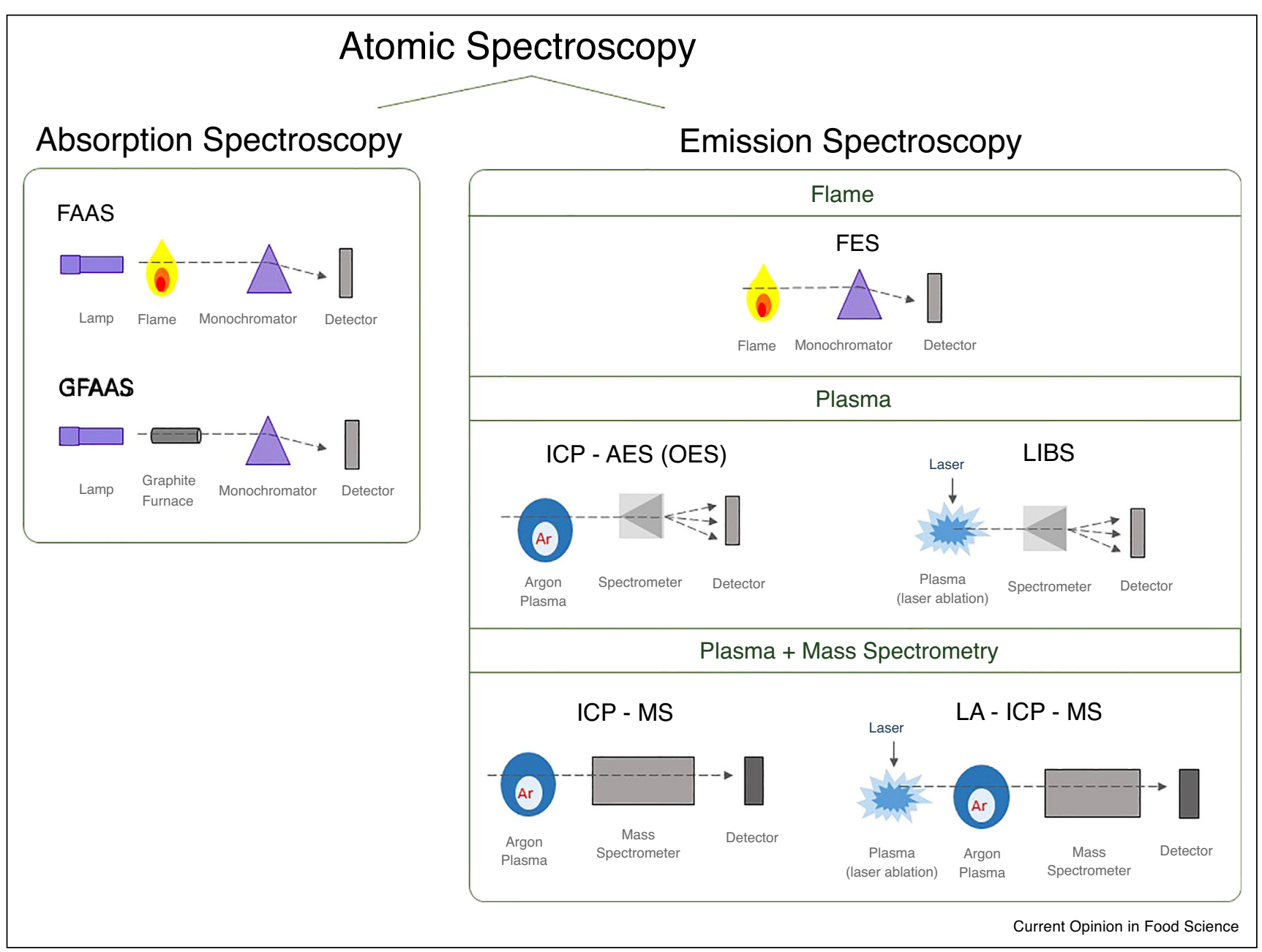

Schematic of an atomic spectroscopy.

and reliable for studying fingerprints of different food products by numerous authors $\left[14,29^{\circ}, 36,44^{\circ}\right]$.

In order to obtain a homogenous sample, food products analysed by LIBS are usually dried, powdered and pressed into the pellet form before the analysis [31]. Depending on the number of shots and accumulation of pulses per shot, sample collection time may take from few seconds to few minutes. Typically, when the spectra are collected in 100 locations with one pulse (accumulation) per location, the collection time takes around $2 \mathrm{~min}$ -1 to $2 \mathrm{~s}$ per shot/location. Although potentially LIBS can analyse liquids, solids and gasses, analysis of liquid samples is challenging as focusing the laser on the liquid surface causes splashing and shockwaves, which affect plasma quality. In order to minimise these effects, new experimental procedures have been proposed. Doublepulse LIBS, LIBS analysis of liquid bulk samples, laminar flows and jets or droplets and aerosol, can improve the experimental configuration. Modular sample chambers designed for liquid analysis are also currently available, which may be helpful in this type of analysis [31]. However, the transformation of liquid to a solid-state by drying or gel formation is still the most common approach and was applied in studies presented in this review.

\section{Applications of LIBS for food authentication}

The substitution of one species by another and the mislabelling of geographic origin are the most common fraudulent practices in food markets [26].

\section{Detection of adulteration by LIBS}

LIBS has been successfully applied to detect adulteration in various foods such as dairy products, meat and coffee. Milk and dairy products adulteration occurs in many 


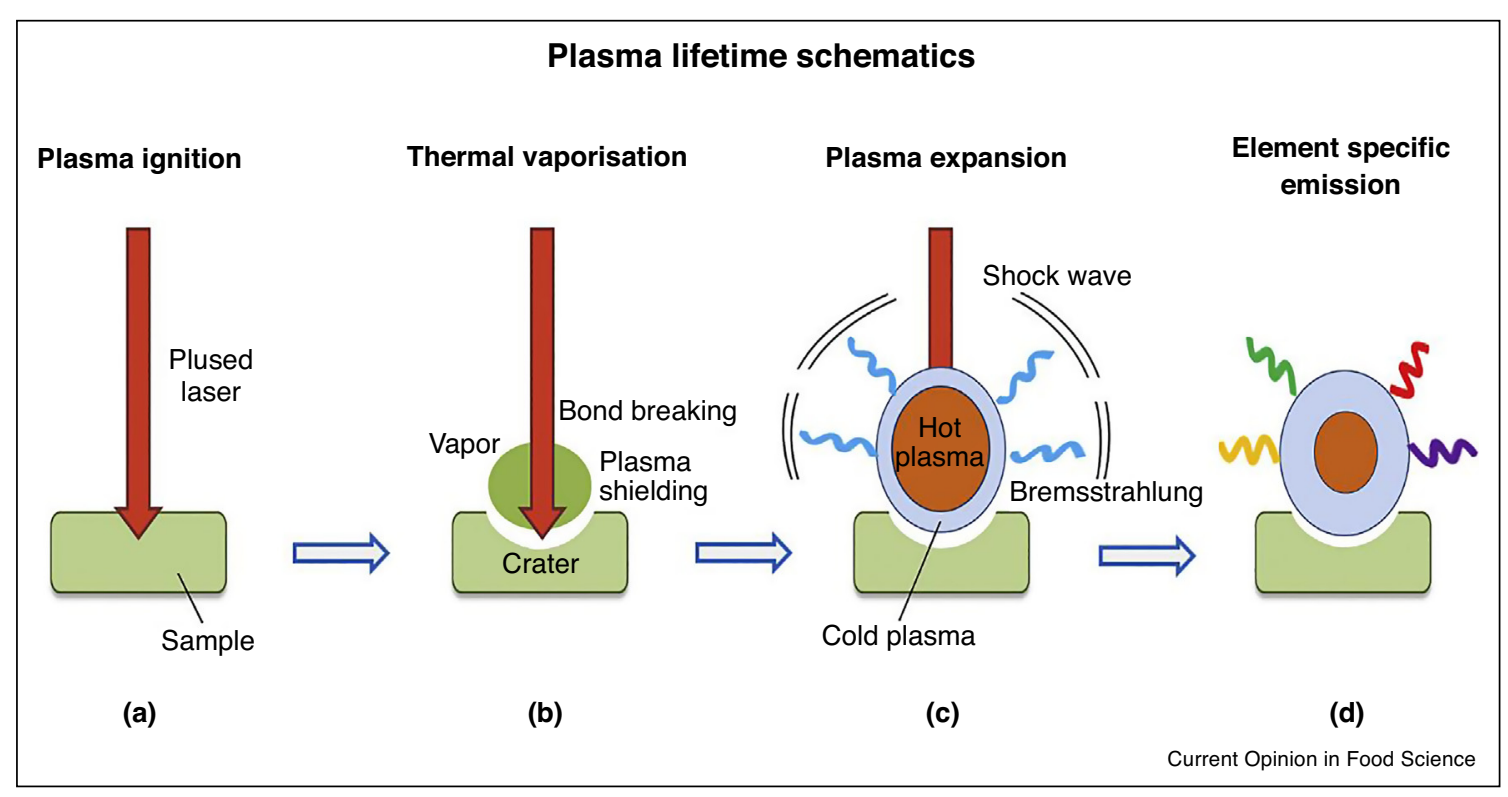

Schematic of the laser-induced breakdown process. The figure has been reproduced from the original paper by Markiewicz-Keszycka et al. [31].

Figure 3

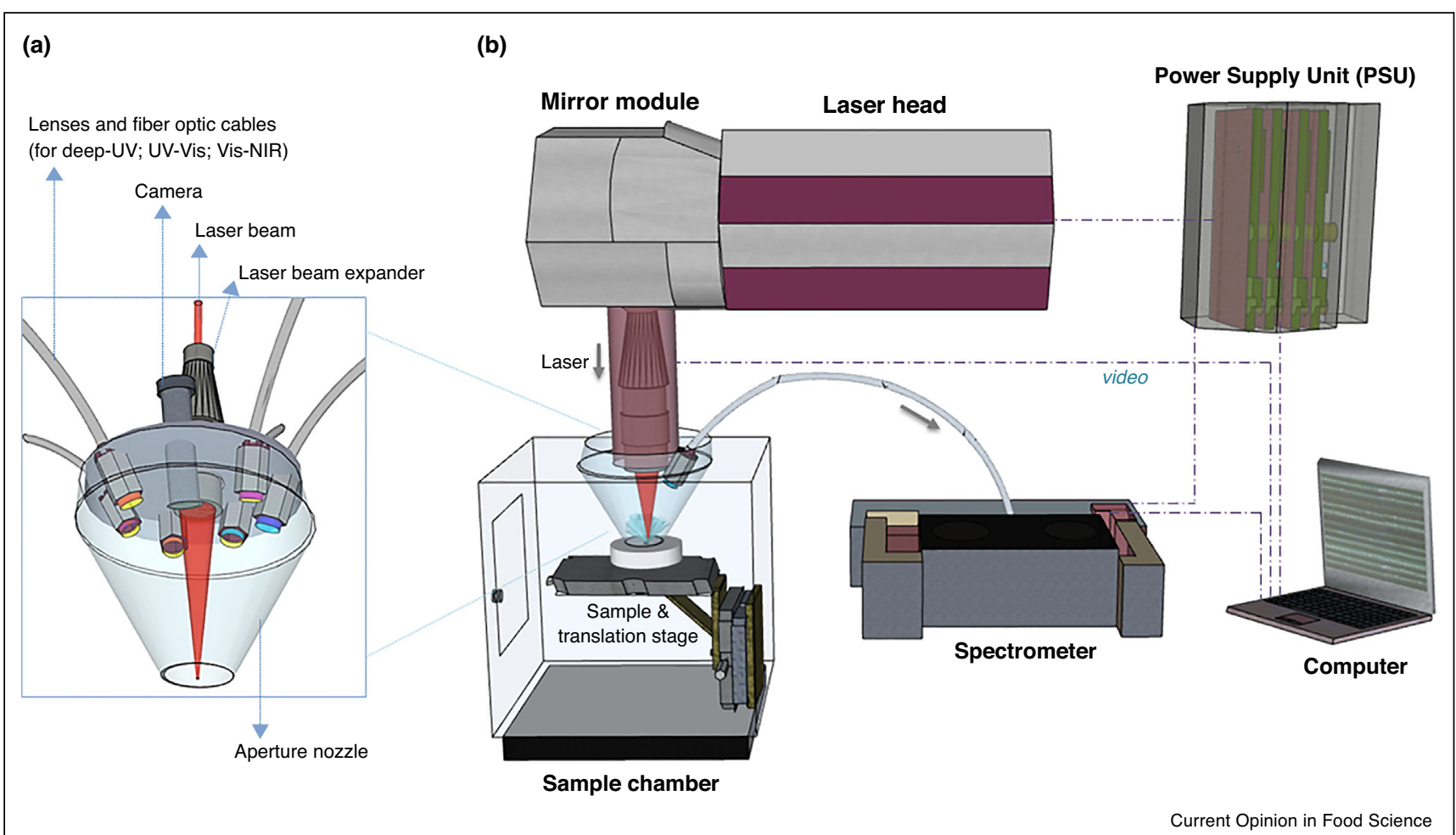

Schematic diagram of the typical LIBS setup. The figure has been reproduced from the original paper by Markiewicz-Keszycka et al. [57]. 
countries [45]. Substitution of more expensive milk with a cheaper alternative, adulteration with fillers, melamine and less costly ingredients are the most common forms of milk and dairy products frauds. Temiz et al. [41] used LIBS coupled to PCA and PLSR to determine butter adulteration with margarine. The intensity differences in spectral lines of $\mathrm{Na}, \mathrm{K}, \mathrm{Fe}, \mathrm{Ca}, \mathrm{Mg}$ and $\mathrm{Mn}$ made an important contribution to successful discrimination analysis. In this study, limit of detection (LOD) and limit of quantification (LOQ) values were $3.9 \%$ and $11.8 \%$ respectively, which was found satisfactory to determine this type of adulteration [41].

Another example highlighting the usefulness of LIBS in food fingerprinting and detection of adulteration is a study of Bilge et al. [33]. The authors used LIBS combined with PCA and PLSR to detect and quantify adulteration of milk powder with whey powder [33]. Sweet and acid whey powders were used as adulterants. The discrimination rate of milk and whey powders was $80.5 \%$. Limit of detection was $1.55 \%$ for sweet whey powder and $0.55 \%$ for acid whey powder.

Similarly, in another study carried out in Turkey, LIBS with chemometrics successfully discriminated caprine and ovine milk adulterated with bovine milk. The limit of detection values for caprine and ovine milk were $1.39 \%$ and $1.29 \%$ respectively [45].

Moncayo et al. evaluated LIBS combined with a neural network (NN) to detect the adulteration of ovine and caprine milk with bovine milk. Powdered samples were prepared by mixing the respective pure milk with the percentages ranging from 25 to $75 \% \mathrm{v} / \mathrm{v}$ of adulterating milk [46]. The LIBS-NN combination allowed $100 \%$ correct classification of blended and pure samples. In the same study, the authors presented the results of an experiment in which LIBS-NN was used to detect melamine in toddler milk powder. Commercial toddler milk was adulterated with melamine at concentrations between $1 \%$ and $6 \%$. A mean prediction error of $5 \%$ was obtained for NN quantitative model in this study. In this case, because of the nature and composition of melamine $\left(\mathrm{C}_{3} \mathrm{H}_{6} \mathrm{~N}_{6}\right)$ its increased concentration was correlated with the $\mathrm{CN}$ molecule emission band [46].

Another widely consumed food is meat. Consumers want to be aware of what type of meat they eat, and accurate labelling is essential to inform their choice. The most common meat adulteration occurs by substitution of original meat species, for example, beef with cheaper meat such as pork [47]. Bilge et al. [33] used LIBS to detect this type of adulteration. The minced beef meat was adulterated with pork or chicken meat at concentrations between $10 \%$ and $50 \%$. The mixtures were analysed with the PLS method. LOD values for chicken adulterated beef and pork adulterated beef were $2 \%$ and $4.4 \%$ respectively [47].
Velioglu et al. used LIBS combined with PCA and PLS to detect offal adulteration in minced beef [34]. CasadoGavalda $e$ al. used LIBS to detect copper as an indicator of the presence of liver in minced beef [48]. These studies reveal that LIBS method combined with chemometrics has the potential to determine the offal adulteration in beef.

Sezer $e t$ al. [49] demonstrated the ability of LIBS combined with chemometrics to detect and quantify coffee adulteration with chickpeas, maize and wheat. Coffee is the second most traded commodity, and as such, it is prone to adulteration practices, such as the addition of certain substances [49]. Blends of coffee arabica with chickpeas, maize and wheat were prepared at ratios between $2.5 \%$ and $60 \%$. LOD values for chickpeas, maize and wheat, were $0.56 \%, 0.52 \%$ and $0.45 \%$ respectively.

\section{Geographical origin}

Because of the globalisation of food markets and increased variability and availability of food products on store shelves, consumers are increasingly interested in the provenance of the foods they consume. The reasons include patriotism, specific culinary quality and decreased confidence in the quality and safety of products of unknown origin or produced outside their region, country or even blocks such as the EU [50]. Moreover, consumers are more and more concerned about the impact of the food they eat on climate [51]. The local food movements encourage people to choose organic, locally grown products which are considered to place less stress on the environment than the conventional food that has travelled a long distance from production to consumer [52]. In the European Union, the originality of certain agricultural products such as wines, tea, honey, rice or olive oils are protected by legislation on the Protected Designation of Origin (PDO) and the Protected Geographic Indications (PGI) [53,54]. These products are often more expensive as they are considered to have unique and exceptional quality; as such, they are among the most likely foods to be the target of food fraud.

Moncayo et al. $\left[35^{\circ}\right]$ used LIBS for the discrimination and the determination of the geographical origin of red wines. Their work aimed to evaluate the feasibility of LIBS combined with NN as a tool for detection the protected designation of origin (PDO) of wines. Thirty-eight red wine samples from different PDOs were analysed to detect fake wines [ $\left.35^{\circ}\right]$. Wine samples were transformed into gels using a commercial collagen. In this study, LIBS demonstrated robustness of $98.6 \%$, high sensitivity of $100 \%$ and generalisation for the determination $-99.2 \%$ of the PDO of red wines.

Tian et al. $\left[44^{\circ}\right]$ used LIBS to perform a classification of French wines from different regions. The authors used the surface-assisted (or surface-enhanced) sample 
preparation method, which enabled detection of 22 metal and non-metal elements. Wine samples were transferred onto a pure aluminium target and dried by evaporation. The residue from a liquid wine in the form of a uniform and semi-transparent thin layer on the aluminium target was analysed by LIBS [44 ${ }^{\circ}$. Fifteen elements were selected as fingerprint elements, and a supervised classification model based on a random forest algorithm was developed. Robust classification results were achieved with a classification accuracy of $100 \%$ [ $\left.44^{\circ}\right]$.

Pérez-Rodríguez et al. [36] investigated spark discharged LIBS (SD-LIBS) to discriminate rice samples according to their PDO. Brown rice samples from two main riceproducing regions in Argentina were analysed by LIBS coupled to a spark discharge. The selection of the spectral data was accomplished by extreme gradient boosting (XGBoost), and the best performance of classification was obtained using k-nearest neighbour (k-NN) algorithm [36]. The authors presented a method that provided $84 \%$ of accuracy, $100 \%$ of sensitivity and $78 \%$ of specificity in the classification of the test samples [36].

\section{Conclusions}

Elemental fingerprinting offers a powerful tool for food authentication and traceability. LIBS technology shows many advantages such as multi-elemental analysis, fast response, low running cost and ease of use. There are many successful examples of the use of this technique for detection of adulterants and geographical origin; however, there is still room for improvement to fully exploit LIBS possibilities not only in the R\&D sector but also in industry and regulatory environments. Development of an agile, robust and cost-efficient tool that is able to detect frauds and geographic origin of food is a considerable challenge needed not only in large enterprises but also in small-scale companies.

However, before establishing LIBS as a validated, an atline or in-field method for food authentication, major improvements are needed. Increase in the sensitivity for trace and rare earth elements detection is a major goal. Most of the studies presented in this review report a spectral signal for 4-7 mineral elements, 4 organic elements and emission bands from diatomic species such as $\mathrm{CN}$ or $\mathrm{C}_{2}$. Higher sensitivity for minor and trace minerals with very low concentrations in a complex organic matrix would increase the usefulness of this method for authentication purposes. Recent advances in the detection of trace and rare earth elements by LIBS $\left[44^{\circ}, 55^{\circ}\right]$ and the continuous development of the technique are expected to give a boost, in the near future, to this detection method. Miniaturisation and the development of a compact, portable LIBS device would provide the possibility for in-situ classification, facilitating the adulteration detection coupled with progress in the quality control of agro-alimentary products. Moreover, improvements need to be made in terms of liquid samples analysis. Transformation of liquids to solids, although very effective, requires additional long sample preparation steps, which impede real-time analysis. Further innovation in LIBS and other optic based technologies, sensor platforms and predictive computation will likely contribute to the development of holistic solutions for food authentication and fraud detection [56].

\section{Conflict of interest statement}

None of the authors of this paper has a financial or personal relationship with other people or organisations that could inappropriately influence or bias the content of the paper.

\section{Acknowledgement}

This work was supported by the Department of Agriculture, Food and the Marine, Ireland (Grant agreement: 14/F/ 866).

\section{References and recommended reading}

Papers of particular interest, published within the period of review, have been highlighted as:

- of special interest

1. Su W-H, Arvanitoyannis IS, Sun D-W: Trends in food authentication. In Modern Techniques for Food Authentication Edited by Sun D-W. Academic Press; 2018:731-758.

2. Ortea I, O'Connor G, Maquet A: Review on proteomics for food authentication. J Proteom 2016, 147:212-225.

3. Danezis GP, Tsagkaris AS, Camin F, Brusic V, Georgiou CA: Food authentication: techniques, trends \& emerging approaches. TrAC - Trends Anal Chem 2016, 85:123-132.

4. Horn B, Esslinger S, Schaarschmidt S, Fauhl-Hassek C: The international symposium "Standardisation of non-targeted methods for food authentication", November 28-29, 2016. Trends Food Sci Technol 2019, 90:166-169.

5. Whitworth E, Druckman A, Woodward A: Food scares: a comprehensive categorisation. Br Food J 2017, 119:131-142.

6. Calbiani F, Careri M, Elviri L, Mangia A, Pistarà L, Zagnoni I: Development and in-house validation of a liquid chromatography- electrospray-tandem mass spectrometry method for the simultaneous determination of Sudan I, Sudan II, Sudan III and Sudan IV in hot chilli products. J Chromatogr A 2004, 1042:123-130.

7. Tsai HJ, Chen BH, Wu CF, Wang SL, Huang PC, Tsai YC, Chen ML, Ho CK, Hsiung CA, Wu MT: Intake of phthalate-tainted foods and microalbuminuria in children: The 2011 Taiwan food scandal. Environ Int 2016, 89-90:129-137.

8. Jacob CJ, Lok C, Morley K, Powell DA: Government management of two media-facilitated crises involving dioxin contamination of food. Public Underst Sci 2011, 20:261-269.

9. Calo-Mata P, Barros-vel J, Karola B, Böhme K, Calo-Mata P, Barros-Velázquez J, Ortea I: Recent applications of omicsbased technologies to main topics in food authentication. TrAC - Trends Anal Chem 2019, 110:221-232.

10. Martini M, Altomonte I, da Silva Sant'ana AM, Del Plavignano G, Salari F: Gross, mineral and fatty acid composition of alpaca (Vicugna pacos) milk at 30 and 60 days of lactation. Small Rumin Res 2015, 132:50-54.

11. Gossner CME, Schlundt J, Embarek P, Ben, Hird S, Lo-FoWong D, Beltran JJO, Teoh KN, Tritscher A: The melamine incident: Implications for international food and feed safety. Environ Health Perspect 2009, 117:1803-1808. 
12. Khedri M, Ramezani M, Rafatpanah H, Abnous K: Detection of food-born allergens with aptamer-based biosensors. TrAC Trends Anal Chem 2018, 103:126-136.

13. Parrilla Vázquez $P$, Ferrer $C$, Martínez Bueno MJ, FernándezAlba AR: Pesticide residues in spices and herbs: sample preparation methods and determination by chromatographic techniques. TrAC - Trends Anal Chem 2019, 115:13-22.

14. Esteki M, Simal-Gandara J, Shahsavari Z, Zandbaaf S, Dashtaki E, Vander Heyden Y: A review on the application of chromatographic methods, coupled to chemometrics, for food authentication. Food Control 2018, 93:165-182.

15. European Parliament and Council: Regulation (EC) $\mathbf{N}^{\circ} 178 / 2002$ of 28 January $\mathbf{2 0 0 2}$ laying down the general principles and requirements of food law, establishing the European Food Safety Authority and laying down procedures in matters of food safety. Off J Eur Commun 2002, L31:1-24.

16. European Union: Regulation (EU) No 1169/2011 of the European Parliament and of the Council on the provision of food information to consumers. Off J Eur Union 2011, L:18-36:18-63.

17. Ballin NZ, Laursen KH: To target or not to target? Definitions and nomenclature for targeted versus non-targeted analytical food authentication. Trends Food Sci Technol 2019, 86:537-543.

18. Ellis DI, Brewster VL, Dunn WB, Allwood JW, Golovanov AP Goodacre R: Fingerprinting food: current technologies for the detection of food adulteration and contamination. Chem Soc Rev 2012, 41:5706-5727.

19. Melini V, Melini F: Asian grain-based food products and the European scheme for food protected designations of origin: a critical analysis. Trends Food Sci Technol 2019, 91:83-94.

20. Ghidini S, Varrà MO, Dall'Asta C, Badiani A, lanieri A, Zanardi E: Rapid authentication of European sea bass (Dicentrarchus labrax L.) according to production method, farming system, and geographical origin by near infrared spectroscopy coupled with chemometrics. Food Chem 2019, 280:321-327.

21. Mandrile L, Zeppa G, Giovannozzi AM, Rossi AM: Controlling protected designation of origin of wine by Raman spectroscopy. Food Chem 2016, 211:260-267.

22. Richter B, Rurik M, Gurk S, Kohlbacher O, Fischer M: Food monitoring: screening of the geographical origin of white asparagus using FT-NIR and machine learning. Food Control 2019, 104:318-325.

23. Monahan FJ, Schmidt O, Moloney AP: Meat provenance:

- authentication of geographical origin and dietary background of meat. Meat Sci 2018, 144:2-14.

The authors review and discuss the feasibility of certain tools such as stable isotope ratio analysis, trace and rare earth elements analysis, determination of specific compounds in meat as indicators (fatty acids, vitamins, volatile compounds) of dietary background and geographical origin.

24. Rizwanullah M, Khan N, Amin S, Ahmad J, Imam SS, Fakhr KU, Rizvi MMA: Introduction to food authentication based on fingerprinting techniques. In Fingerprinting Techniques in Food Authentication and Traceability. Edited by Siddiqi KS, Nollet ML. CRC press; 2018:143-167.

25. Abbas $O$, Zadravec M, Baeten V, Miku T, Le T, Vuli A, Mikuš T, Lešić T, Vulić A, Prpić J et al.: Analytical methods used for the authentication of food of animal origin. Food Chem 2018, 246:6-17.

26. Tariq A, Bhawan AS, Husaini A, Moheman A: Authentication and traceability of rice. In Fingerprinting Techniques in Food Authentication and Traceability. Edited by Siddiqi KS, Nollet ML. CRC Press; 2019.

27. Kamiloglu S: Authenticity and traceability in beverages. Food Chem 2019, 277:12-24.

28. Chudzinska M, Baralkiewicz D: Estimation of honey authenticity by multielements characteristics using inductively coupled plasma-mass spectrometry (ICP-MS) combined with chemometrics. Food Chem Toxicol 2010, 48:284-290.

29. Zhou X, Taylor MP, Salouros H, Prasad S: Authenticity and - geographic origin of global honeys determined using carbon isotope ratios and trace elements. Sci Rep 2018, 8:1-11.
In this study authors use stable carbon isotope ratio and trace element analysis for geographic authentication of honeys. They demonstrate that trace elements such as Sr, P, Mn and $\mathrm{K}$ can be used to differentiate honey according to its geographic origin.

30. Reinholds I, Bartkevics V, Silvis ICJ, van Ruth SM, Esslinger S: Analytical techniques combined with chemometrics for authentication and determination of contaminants in condiments: a review. J Food Compos Anal 2015, 44:56-72.

31. Markiewicz-Keszycka M, Cama-Moncunill X, CasadoGavalda MP, Dixit Y, Cama-Moncunill R, Cullen PJ, Sullivan C: Laser-induced breakdown spectroscopy (LIBS) for food analysis: a review. Trends Food Sci Technol 2017, 65:80-93.

32. Cama-Moncunill R, Casado-Gavalda MP, Cama-Moncunill X, Markiewicz-Keszycka M, Dixit Y, Cullen PJPJ, Sullivan C: Quantification of trace metals in infant formula premixes using laser-induced breakdown spectroscopy. Spectrochim Acta Part B Atom Spectrosc 2017, 135:6-14.

33. Bilge G, Sezer B, Eseller KE, Berberoglu H, Topcu A, Hakki I, Boyaci IH, Efe K, Berberoglu H, Topcu A et al.: Determination of whey adulteration in milk powder by using laser induced breakdown spectroscopy. Food Chem 2016, 212:183-188.

34. Velioglu HM, Sezer B, Bilge G, Baytur SE, Boyaci IH, Veliogu MH, Sezer B, Bilge G, Baytur ES, Boyaci HI: Identification of offal adulteration in beef by laser induced breakdown spectroscopy (LIBS). Meat Sci 2018, 138:28-33.

35. Moncayo S, Rosales JD, Izquierdo-hornillos R, Anzano J,

- Caceres JO: Classification of red wine based on its protected designation of origin (PDO) using laser-induced breakdown spectroscopy (LIBS). Talanta 2016, 158:185-191.

Authors used LIBS coupled with Neural Networks for the quality control of red wines with protected designation of origin (PDO). Tested wines were transformed into gels and classified/discriminated based on their characteristic spectral fingerprints. This study indicated for the first time that LIBS can be successfully employed for the identification of geographical origin of food.

36. Pérez-Rodríguez M, Dirchwolf PM, Silva TV, Villafañe RN Neto JAG, Pellerano RG, Ferreira EC, Maia P, Varão T, Noelia R et al.: Brown rice authenticity evaluation by spark dischargelaser-induced breakdown spectroscopy. Food Chem 2019, 297 124960.

37. Rehse SJ: A review of the use of laser-induced breakdown spectroscopy for bacterial classification quantification and identification.pdf. Spectrochim Acta Part B 2019, 154:50-69.

38. Borges EM, Volmer DA, Brandelero E, Lafayette Neves Gelinski JM, Gallimberti M, Barbosa F: Monitoring the authenticity of organic grape juice via chemometric analysis of elemental data. Food Anal Methods 2016, 9:362-369.

39. de Carvalho GGA, Santos D Jr, da Silva Gomes M, Nunes LC, Guerra MBB, Krug FJ: Influence of particle size distribution on the analysis of pellets of plant materials by laser-induced breakdown spectroscopy. Spectrochim Acta Part B Atom Spectrosc 2015, 105:130-135.

40. Lee Y, Nam SH, Ham KS, Gonzalez J, Oropeza D, Quarles D, Yoo J, Russo RE: Multivariate classification of edible salts: simultaneous laser-induced breakdown spectroscopy and laser-ablation inductively coupled plasma mass spectrometry analysis. Spectrochim Acta Part B Atom Spectrosc 2016, 118:102-111.

41. Temiz HT, Sezer B, Berkkan A, Tamer U, Boyaci IH: Assessment of laser induced breakdown spectroscopy as a tool for analysis of butter adulteration. J Food Compos Anal 2018 67:48-54.

42. Canizo BV, Escudero LB, Pérez MB, Pellerano RG, Wuilloud RG: Intra-regional classification of grape seeds produced in Mendoza province (Argentina) by multi-elemental analysis and chemometrics tools. Food Chem 2018, 242:272-278.

43. Yang P, Zhu Y, Yang X, Li J, Tang S, Hao Z, Guo L, Li X, Zeng X, Lu Y: Evaluation of sample preparation methods for rice geographic origin classification using laser-induced breakdown spectroscopy. J Cereal Sci 2018, 80:111-118.

44. Tian Y, Yan C, Zhang T, Tang H, Li H, Yu JJ, Bernard J, Chen L,

- Martin S, Delepine-Gilon N et al.: Classification of wines 
according to their production regions with the contained trace elements using laser-induced breakdown spectroscopy. Spectrochim Acta Part B Atom Spectrosc 2017, 135:91-101. In this paper laser-induced breakdown spectroscopy (LIBS) was used to classify French wines according to their production regions. Interesting approach of the surface-assisted (or surface-enhanced) sample preparation is presented in this study. The method allowed a sub ppm limit of detection and identification of at least 22 metal and non-metal elements including majors, minors and traces.

45. Sezer B, Durna S, Bilge G, Berkkan A, Yetisemiyen A, Boyaci IH: Identification of milk fraud using laser-induced breakdown spectroscopy (LIBS). Int Dairy J 2018, 81:1-7.

46. Moncayo S, Manzoor S, Rosales JD, Anzano J, Caceres JO: Qualitative and quantitative analysis of milk for the detection of adulteration by laser induced breakdown spectroscopy (LIBS). Food Chem 2017, 232:322-328.

47. Bilge G, Velioglu HM, Sezer B, Eseller KE, Boyaci IH, Murat H, Sezer B, Efe K, Hakki I: Identification of meat species by using laser-induced breakdown spectroscopy. Meat Sci 2016, 119:118-122.

48. Casado-Gavalda MP, Dixit Y, Geulen D, Cama-Moncunill R, Cama-Moncunill X, Markiewicz-Keszycka M, Cullen PJ, Sullivan C: Quantification of copper content with laser induced breakdown spectroscopy as a potential indicator of offal adulteration in beef. Talanta 2017, 169:123-129.

49. Sezer B, Apaydin H, Bilge G, Boyaci IH: Coffee arabica adulteration: detection of wheat, corn and chickpea. Food Chem 2018, 264:142-148.

50. Camin F, Boner M, Bontempo L, Fauhl-Hassek C, Kelly SD, Riedl J Rossmann A: Stable isotope techniques for verifying the declared geographical origin of food in legal cases. Trends Food Sci Technol 2017, 61:176-187.

51. Adewale C, Reganold JP, Higgins S, Evans RD, CarpenterBoggs L: Improving carbon footprinting of agricultural systems: boundaries, tiers, and organic farming. Environ Impact Assess Rev 2018, 71:41-48.

52. Gil JDB, Daioglou V, van Ittersum M, Reidsma P, Doelman JC, van Middelaar CE, van Vuuren DP: Reconciling global sustainability targets and local action for food production and climate change mitigation. Global Environ Change 2019, 59101983.

53. Slačanac V, Božanić R, Hardi J, Rezessyné Szabó J, Lučan M, Krstanović V: Nutritional and therapeutic value of fermented caprine milk. Int J Dairy Technol 2010, 63:171-189.

54. Drivelos SA, Georgiou CA: Multi-element and multi-isotoperatio analysis to determine the geographical origin of foods in the European Union. TrAC - Trends Anal Chem 2012, 40:38-51.

55. Gaft M, Raichlin Y, Pelascini F, Panzer G, Motto Ros V: Imaging

- rare-earth elements in minerals by laser-induced plasma spectroscopy: molecular emission and plasma-induced luminescence. Spectrochim Acta Part B Atom Spectrosc 2019, 151:12-19.

In this paper, the authors present the approach that combines LIBS technique with the molecular emissions of $\mathrm{LaO}$ and $\mathrm{YO}$ and the plasmainduced luminescence (PIL) of REEs in luminescent matrixes. The described experiments (atomic LIBS, molecular LIBS and PIL) were performed with the same experimental setup and from the same plasma source. Only the detection parameters (spectral range and spectrometer slit, as well as the ICCD gain, delay and width) were modified. The authors demonstrated that such an approach could lead to more sensitive imaging and detection of REEs in geological samples.

56. Ellis DI, Muhamadali H, Haughey SA, Elliott CT, Goodacre R: Point-and-shoot: rapid quantitative detection methods for onsite food fraud analysis-moving out of the laboratory and into the food supply chain. Anal Methods 2015, 7:9401-9414.

57. Markiewicz-Keszycka M, Zhao M, Cama-moncunill X, El Arnaout T, Becker D, O'Donnell C, Cullen PJ, Sullivan C, Casadogavalda MP, Donnell CO et al:: Rapid analysis of magnesium in infant formula powder using laser-induced breakdown spectroscopy. International Dairy Journal 2019, 97:57-64. 